\title{
Peningkatan Rank Webometrics Menggunakan Metode Inbound Dan Outbound Pada Perguruan Tinggi
}

\section{Increased Webometrics Rank with Inbound and Outbound Methods in Higher Education}

\author{
Untung Rahardja ${ }^{1}$, Endah Nirmala Dewi ${ }^{2}$, Ninda Lutfiani ${ }^{3}$ \\ Alumni Universitas Indonesia Program Studi Magister Teknologi Informasi ${ }^{1}$, Mahasiswa \\ STMIK Raharja Jurusan Sistem Informasi ${ }^{2}$, Mahasiswa STMIK Raharja Jurusan Sistem \\ Informasi ${ }^{3}$ \\ $\underline{\text { untung@raharja.info }}^{1},{\underline{\text { endah@ } \text { raharja.info }^{2}}} \underline{\text { ninda@ }}^{\text {raharja.info }}{ }^{3}$
}

\begin{abstract}
Abstrak
Pesatnya perkembangan Teknologi Informasi saat ini memiliki peranan yang sangat penting dalam peningkatan daya saing perguruan tinggi yang berkualitas. Untuk mengetahui kualitas dan peringkat suatu perguruan tinggi terbaik maka diperlukan adanya parameter. Pemeringkatan webometrics adalah salah satu parameter penilaian terhadap kinerja web universitas dunia yang semakin menjadi perhatian khusus di kalangangan akademisi. Sebagai lembaga pendidikan yang mengedepankan ilmu komputer dengan selalu mengutamakan mutu, Perguruan Tinggi Raharja juga turut serta dalam peringkat webometrics untuk bersaing dengan perguruan tinggi tingkat dunia. Webometrics memberikan informasi mengenai kualitas suatu web universitas yang didukung dengan adanya subdomain dari domain utama yang dimiliki setiap universitas yang sudah mendaftarkan untuk bisa masuk dalam ranking webometrics ini. Semakin kecil rank yang di dapat maka semakin besar peluang untuk menduduki peringkat atas. Adapun kriteria atau level yang dibuat menggunakan metode pendekatan obyek 10 level inbound, hal ini untuk memudahkan penyebaran link agar sesuai dengan target yang diharapkan dan lebih meluas sehingga mencapai hasil yang maksimal untuk mencapai predikat perguruan tinggi yang masuk dalam World Class University (WCU).
\end{abstract}

Kata kunci-Webometrics, Inbound dan Outbound

\begin{abstract}
The rapid development of information technology today has a very important role in improving the competitiveness of higher education quality. To determine the quality and ranking of the best universities will be needed parameters. Webometrics ranking is one of the parameters for evaluating the web performance of world universities are increasingly becoming special attention in academia. As an educational institution that emphasizes computer science to always give priority to quality, Higher Education Prog also participated in the Webometrics rankings to compete with world-class universities. Webometrics provide information about the quality of a university web supported by the sub-domain of the main domain to which every university already registered to be included in this ranking Webometrics. The lower the rank in the can, the greater the opportunity to occupy top rankings. The criteria or level are made using the method object approaches the 10-level inbound, this is to facilitate the deployment of a link to match the expected target and extensively so as to achieve maximum results for the predicate incoming college in the World Class University (WCU).
\end{abstract}

Keywords - Webometrics, Inbound and Outbound

\section{PENDAHULUAN}

Penilaian kinerja web universitas saat ini menjadi perhatian khusus setiap civitas akademik setelah adanya pemeringkatan webometrics yang menjadi parameter. Pemeringkatan web atau webometrics merupakan pemeringkatan akademik terbesar untuk institusi perguruan tinggi. Sejak tahun 2004, setiap 6 bulan, Cybermetrics Lab melakukan penilaian secara independen, obyektif, bebas, dan terbuka untuk menyediakan informasi yang handal, multidimensi, terbarukan dan berguna tentang kinerja perguruan tinggi dari seluruh dunia 
berdasarkan kehadiran web dan dampaknya. Webometrics tidak bertujuan untuk mengevaluasi sebuah website, seperti desain, kebergunaannya atau popularitas isi terhadap jumlah pengunjung (Wahyuningrum, 2015) ${ }^{[1]}$. Data pada periode pertama di bulan Januari 2016, Webometrics telah melakukan pemeringkatan pada lebih dari 20.000 perguruan tinggi di dunia (482 perguruan tinggi dari Indonesia).

Data terakhir untuk web domain utama Perguruan Tinggi Raharja yaitu raharja.ac.id menduduki peringkat 18.495 tingkat dunia dan peringkat yang didapat berdasarkan perhitungan di negara Indonesia sendiri, Perguruan Tinggi Raharja menduduki peringkat ke 303. Bercermin pada hasil tersebut, hal ini menjadi permasalahan bagaimana upaya untuk meningkatkan peringkat Perguruan Tinggi Raharja pada webometrics, dan ini akan dikupas secara mendetail dalam karya ilmiah ini.

Langkah yang diambil adalah dengan memenuhi salah satu indikator penilaian webometrics yaitu visibility, banyak link yang dihitung oleh mesin pencari seperti google. Untuk mencapai indikator tersebut dijembatani dengan penyebaran link dan di klasifikasikan dengan membentuk 10 level inbound link, dan memaksimalkan keberadaan outbound link yang terdapat pada setiap domain yang berada dibawah web domain utama raharja.ac.id. Pada gambar 1 terlihat perbedaan antara inbound dan outbound link.

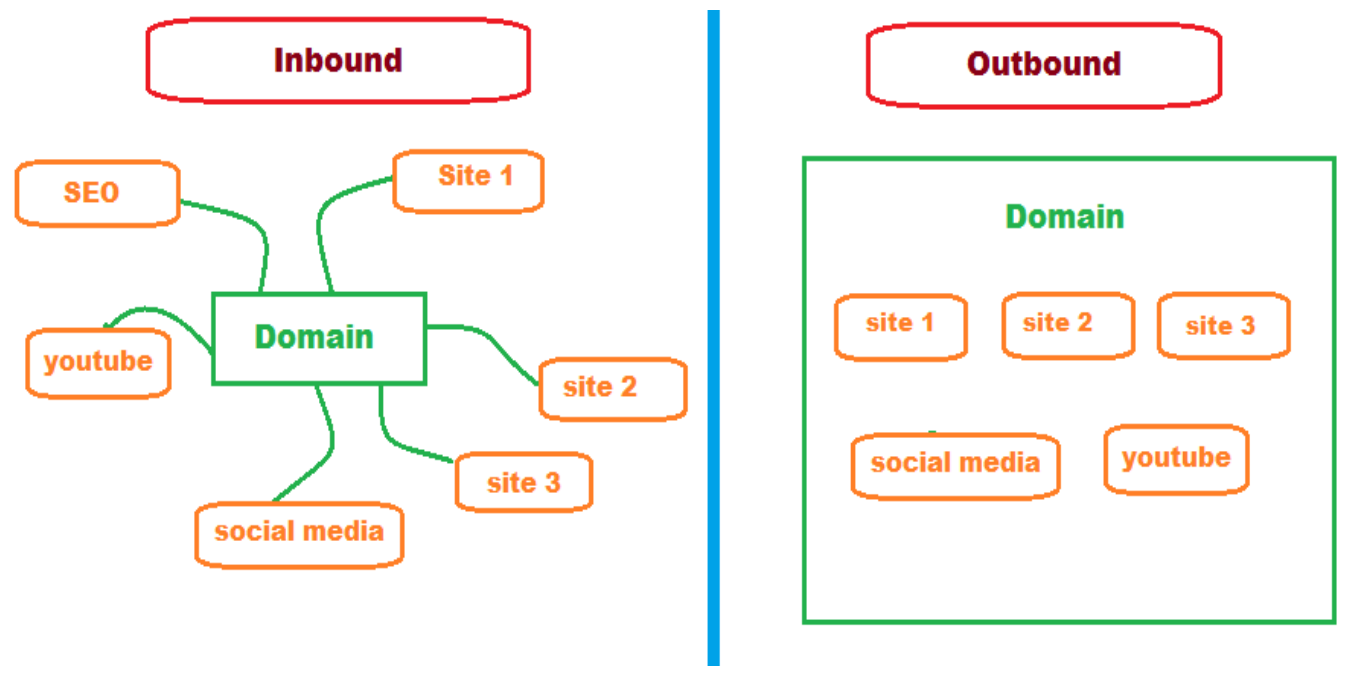

Gambar 1. Inbound dan Outbound

Tampak pada gambar satu, menjelaskan antara inbound dan outbound link dimana pada sisi Inbound terdapat sebuah web domain yang menebarkan link pada banyak website, sosial media dan youtube yang juga memanfaatkan SEO (Search Engine Optimization) supaya dapat ditampilkan pada halaman pertama mesin pencari. Disisi lain terdapat gambaran Outbound, sebuah webdomain yang didalamnya terdapat link untuk menuju ke website atau blog lain, dan tidak lupa juga mencantumkan jejaring sosial serta video youtube yang dimiliki. Untuk mewujudkan World Class University (WCU) tentu perlu ada teamwork dan ini menjadi tanggung jawab bersama setiap civitas Perguruan Tinggi Raharja, seluruhnya memegang peranan penting dan memiliki porsi yang sama dengan tujuan satu yaitu memaksimalkan setiap sub-domain yang berada dibawah naungan webdomain utama.

Dengan menjadi bagian dari webometrics, berarti Perguruan Tinggi Raharja siap untuk menjadi salah satu perguruan tinggi yang memiliki performa serta lalu lintas website yang terbaik di Indonesia hingga bersaing dengan universitas baik dunia. Namun untuk mewujudkan cita-cita tersebut diperlukan banyak usaha hingga bisa memenuhi setiap indikator yang diberikan oleh webometrics. Oleh karena itu dengan adanya metode inbound dan outbound yang diterapkan, sebagai salah satu upaya untuk bisa memenuhi indikator visibility dapat mendukung dalam peningkatan rank webometrics. 
Dalam penelitian ini dilakukan tinjuan pustaka terhadap penelitian terdahulu, untuk mengetahui perbedaan dengan penelitian sebelumnya. Adapun empat penelitian yang ada yaitu: a) Penelitian yang dilakukan oleh Adelakun (2013) "Webometrics Rankings As Informer Of Public Policy On University Education: Some Implications For Nigeria's Economic Growth". Kegunaan dari webometrics dalam implikasi pertumbuhan ekonomi Nigeria. faktor dampak web dan kelulusan tarif, adanya diskon esensi. Dalam konteks ini penelitia digunakan sebagai penunjang dampak suatu web dan kegiatan penumbuhan ekonomi di Nigeria. Sedangkan dalam penelitian ini Webometrics digunakan sebagai alat ukur untuk mengukur popularias Perguruan Tinggi Raharja dalam dunia maya dan sejauh apa strategi linking berjalan. ${ }^{[2]}$; b) Penelitian yang dilakukan oleh Swaminathan Jeyashree1 dan Rajaiyan Ravichandran (2013) dengan judul "Perspectives of Webometric Tools for Web Impact Assessment Studies: A Review". Dalam penelitian ini membahas juga alat digunakan Bing Application Programming Interface (API) untuk menarik kembali semua URL (sub domain) langsung ke hard disk yang akan berguna untuk analisis data lebih lanjut. 'Analyst Webometric' dimanfaatkan API Bing secara gratis, fasilitas pencarian dan memiliki berbagai fungsi inbuilt yang lengkap. Perbedaan dengan penelitian sebelumnya terletak pada penyebara link yang sudah tidak menggunakan harddisk. ${ }^{[3]}$; c) Penelitian ini dilakukan oleh O. Osunade C.O. Ogundele, yang berjudul "EVALUATION OF THE UNIVERSITY OF IBADAN WEBSITE USING WEBOMETRIC RANKING PARAMETARS” (2012) dalam Internasnational Journal of Science and Technology. Dalam penelitian tersebut menjelaskan hasil dari webometric di tahun 2011, situs Universitas Ibadan merosot ke posisi sebelas. Universitas lakukan berbagai langkah untuk mendapatkan kembali posisi pertama di Nigeria. Pada penelitian ini memanfaatkan kekayaan file digital, ukuran, Google Scholar dan visibilitas yang dimiliki Universitas Ibadan. Sedangkan dalam penelitian ini menggunakan strategi inbound dan outbound sebagai langkah untuk meningkatkan peringkat webometrics. ${ }^{[4]}$; d) Penelitian ini dilakukan oleh Liwen Vaughan dan Rongbin Yang, pada tahun 2013 yang berjudul "Web traffic and organization performance measures: Relationships and data sources examined". Dalam penelitian ini membahas hubungan antara data lalu lintas Web dan langkah-langkah akademik/kinerja bisnis. Meskipun berbagai sumber data lalu lintas yang ada, beberapa studi telah meneliti dan membandingkan manfaat relatifnya. Penelitian ini bertujuan untuk mengatasi kekurangan tersebut dengan memilih kelompok universitas dan bisnis dari AS dan China serta mengumpulkan data lalu lintas Web dari tiga sumber: Alexa Internet, Google Trends untuk Situs Web, dan Bersaing. Perbedaan dalam penelitian ini dimana adanya mind mapping sebagai langkah perancangan strategi inbound dan outbound. ${ }^{[5]}$

\section{METODE PENELITIAN}

Tahapan yang digunakan dalam penyusunan penelitian ini menggunakan metode pengumpulan data, sebagai berikut.

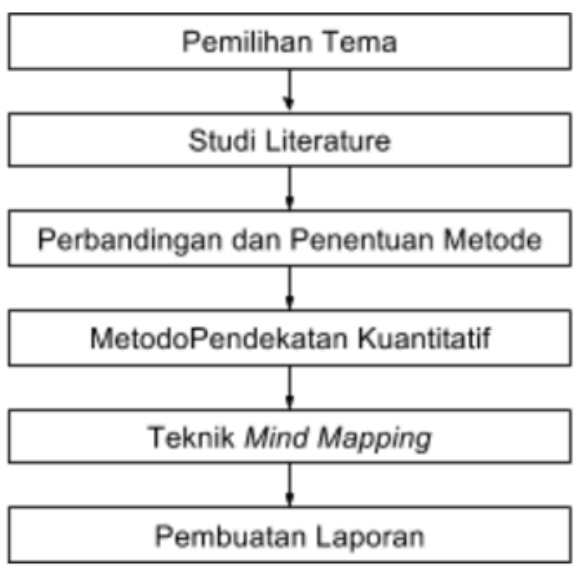

Gambar 2. Tahapan Penyusunan Penelitian 
Keterangan :

1. Pemilihan tema dengan cara memilih dan menentukan terlebih dahulu permasalahan atau tema penelitian yang akan diambil.

2. Studi Literatur, metode yang digunakan mendapatkan data dengan cara melihat, membaca, serta mengembangkan informasi yang berkaitan pada masalah yang dibicarakan sebagai referensi serta penunjang penelitian.

3. Perbandingan antar metode, membandingan antar metode serta indikator webometrics, guna mendapatkan motode yang tepat untuk dapat diimplementasikan pada proses pemeringkatan webometrics khususnya Perguruan Tinggi Raharja.

4. Metodologi yang digunakan adalah melalui pendekatan kuantitatif untuk mengetahui peringkat website perguruan tinggi melalui metode webometrics dengan fokus pada indikator visibility. Subjek penelitian ini adalah web domain perguruan tinggi beserta subdomainnya, sedangkan objek penelitian ini adalah Perguruan Tinggi Raharja.

5. Teknik Mind Mapping bertujuan untuk membuat informasi yang disampaikan menjadi lebih mudah dipahami

6. Laporan ditulis dalam bentuk dokumen setelah semua penelitian terselesaikan.

\section{HASIL DAN PEMBAHASAN}

\subsection{Analisa Permasalahan}

Melihat pada setiap indikator berbobot pada penilaian untuk meningkatkan rank pada webometrics yaitu sebagai berikut:

1. Presence

adalah total jumlah halaman webhost dalam webdomain utama (termasuk semua subdomain dan direktori) yang diindeks oleh mesin pencari Google. (bobot 10\%)

2. Visibility

adalah mengambil nilai dari inlinks provider (majestic) dengan menggunakan rata-rata. (bobot 50\%)

3. Openness

adalah total jumlah file (.pdf,.doc,.docs,.ppt,.pptx,) yang online/open dibawah domain website universitas yang tertangkap oleh mesin pencari. (bobot 10\%)

4. Excellence

adalah data dari scimago, terdapat lebih dari 10\% artikel ilmiah yang di sitir (cited) dari berbagai disiplin ilmu untuk periode lima tahun. (bobot30\%)

Berdasarkan keterangan dari setiap indikator penilaian webometrics diatas, dimana yang menjadi penilaian terbanyak ada pada visibility yang memiliki bobot sebanyak $50 \%$ hal ini baiknya menjadi fokus awal untuk dapat dicapai dengan maksimal. Berikut ini adalah hasil capaian pemeringkatan Webometrics pada edisi Januari 2016 yang mana ini menjadi acuan untuk strategi selanjutnya guna menaikkan peringkat Perguruan Tinggi Raharja pada edisi Juli 2016.

Tabel 1: Pencapaian rank webometrics bulan Januari 2016

\section{Search results}

\section{Indonesia}

\begin{tabular}{|c|c|c|c|c|c|c|c|c|}
\hline Ranking & $\begin{array}{l}\text { World } \\
\text { Ranking }\end{array}$ & University & Det. & Country & Presence & Impact & Openness & Excellence \\
\hline 303 & 18495 & $\begin{array}{l}\text { Perquruan Tingai } \\
\text { Raharia }\end{array}$ & Ex & $\square$ & 12846 & 19730 & 12445 & 5484 \\
\hline
\end{tabular}


Berdasarkan tabel diatas dapat dilihat bahwa Perguruan Tinggi Raharja menduduki peringkat ke 303 untuk kategori per-negara Indonesia pada periode Januari 2016 yang lalu, sedangkan di tingkat dunia menduduki peringkat ke 18.495. Diketahui Impact/visibility yang menjadi fokus disini sejumlah 19.730, Indikatornya adalah perkalian dari akar kuadrat jumlah backlink dan jumlah domain yang berasal dari backlink mereka, sehingga tidak hanya mementingkan popularitas link, tetapi lebih dari keragaman hubungan. Maksimum dari hasil normalisasi adalah indikator impact (Tenia, 2015).

$$
\text { impact }=\sqrt{\sum \text { backlinks }} \times \sum \text { domains }
$$

Keterangan :

Impact $=$ indikator impact

$\sum$ backlinks $=$ jumlah backlink

$\sum$ domain $=$ jumlah domain yang berasal dari backlink

Metode Inbound dan Outbound sebagai langkah melalui proses yang sederhana dan mudah namun jika dilakukan secara berkala dan adanya target yang ditentukan maka akan semakin memperluas jangkauan untuk Perguruan Tinggi Raharja dapat bersinar dengan kualitas website terbaik hingga mampu mencapai kesuksesan webometrics.

3.2 Pemecahan Masalah

Sebagai langkah untuk memecahkan permasalahan yang ada, yaitu dengan pengelolaan setiap halaman website yang baik pada raharja.ac.id. Penyebaran link atau yang biasa dikenal dengan sebutan linking. Seperti yang sudah dijabarkan sebelumnya bahwa pembobotan dengan angka tertinggi dalam penilaian webometrics adalah visibility.

Untuk mempermudah pendokumentasian dan publikasi informasi, maka dibuatlah subdomain yang memiliki beragam fungsi. Dari 21 (dua puluh satu) subdomain yang berada dibawah naungan domain utama yaitu raharja.ac.id, masing-masing telah mengandung kata kunci/keyword. Dengan demikian, mesin pencari akan mudah mendapatkan informasi berdasarkan keyword yang diberikan

Penempatan setiap informasi di kalsifikasikan sesuai dengan kebutuhan. Seperti info per-jurusan, website seputar fasilitas dan pelayanan yang dikhususkan untuk memberikan informasi dibidang tersebut. Subdomain aktifitas akademik, akan dikhususkan pada kegiatan akademik seperti sistem iLearning yang menjadi metode pembelajaran yang banyak diminati oleh mahasiswa, begitu juga sistem pembelajaran iLearning Plus Perguruan Tinggi Raharja.

Tabel 2. Daftar 21 subdomain dan peruntukannya

\begin{tabular}{lcc}
\hline No & Peruntukan Domain & Nama Domain \\
\hline 1. & Facility Information Service & fasilitas.raharja.ac.id \\
\hline 2. & Public Relation Support And Campus Activity & greendoc.raharja.ac.id \\
\hline 3. & Program Study Information (SI) & si.raharja.ac.id \\
\hline 4. & Program Study Information (TI) & ti.raharja.ac.id \\
\hline 5. & Program Study Information (SK) & sk.raharja.ac.id \\
\hline 6. & Program Study Information (KA) & ka.raharja.ac.id \\
\hline 7. & Program Study Information (TI D3) & tid3.raharja.ac.id \\
\hline
\end{tabular}


Peningkatan Rank Webometrics Menggunakan Metode Inbound Dan Outbound ...

\begin{tabular}{lcc}
\hline 8. & Program Study Information $(\mathrm{MI})$ & mi.raharja.ac.id \\
\hline 9. & Program Study Information (MTi) & mti.raharja.ac.id \\
\hline 10. & Student Activity & kemahasiswaan.raharja.ac.id \\
\hline 11. & Alumni & alumni.raharja.ac.id \\
\hline 12. & Logistic Information & logistik.raharja.ac.id \\
\hline 13. & School Relation & pmb.raharja.ac.id \\
\hline 14. & iLearning Plus Information & ilp.raharja.ac.id \\
\hline 15. & Quality Assurance information & mutu.raharja.ac.id \\
\hline 16. & Research Information & rec.raharja.ac.id \\
\hline 17. & Repository Management & repository.raharja.ac.id \\
\hline 18. & Journal Publication & journal.raharja.ac.id \\
\hline 19. & Competency Publication & tuk.raharja.ac.id \\
\hline 20. & Graphic, Desain adn Video & mavib.raharja.ac.id \\
\hline 21. & dosen.raharja.ac.id \\
\hline
\end{tabular}

Untuk merancang sebuah konsep pencapaian visibility webometrics, menggunakan metode inbound dan outbound ini, penulis telah membuat sebuah kerangka Mind Mapping agar pencapaian lebih jelas dan struktur. Disamping itu, Mind Mapping sendiri adalah cara untuk menggambarkan informasi ke dalam pikiran untuk mengambil informasi keluar dari pikiran, sehingga kretifitas akan muncul.

Mind Mapping memiliki tampilan yang menyenangkan untuk dilihat, dibaca, dicerna dan mudah diingat. Dengan Mind Mapping, daftar informasi yang panjang bisa dialihkan menjadi diagram yang lebih fresh karena didominasi dengan beberapa warna, sangat teratur dan hal ini selaras dengan cara kerja alami otak dalam melakukan berbagai hal. Diharapkan Penggunaan konsep Mind Mapping agar dapat membuat informasi yang disampaikan menjadi lebih mudah dipahami. 


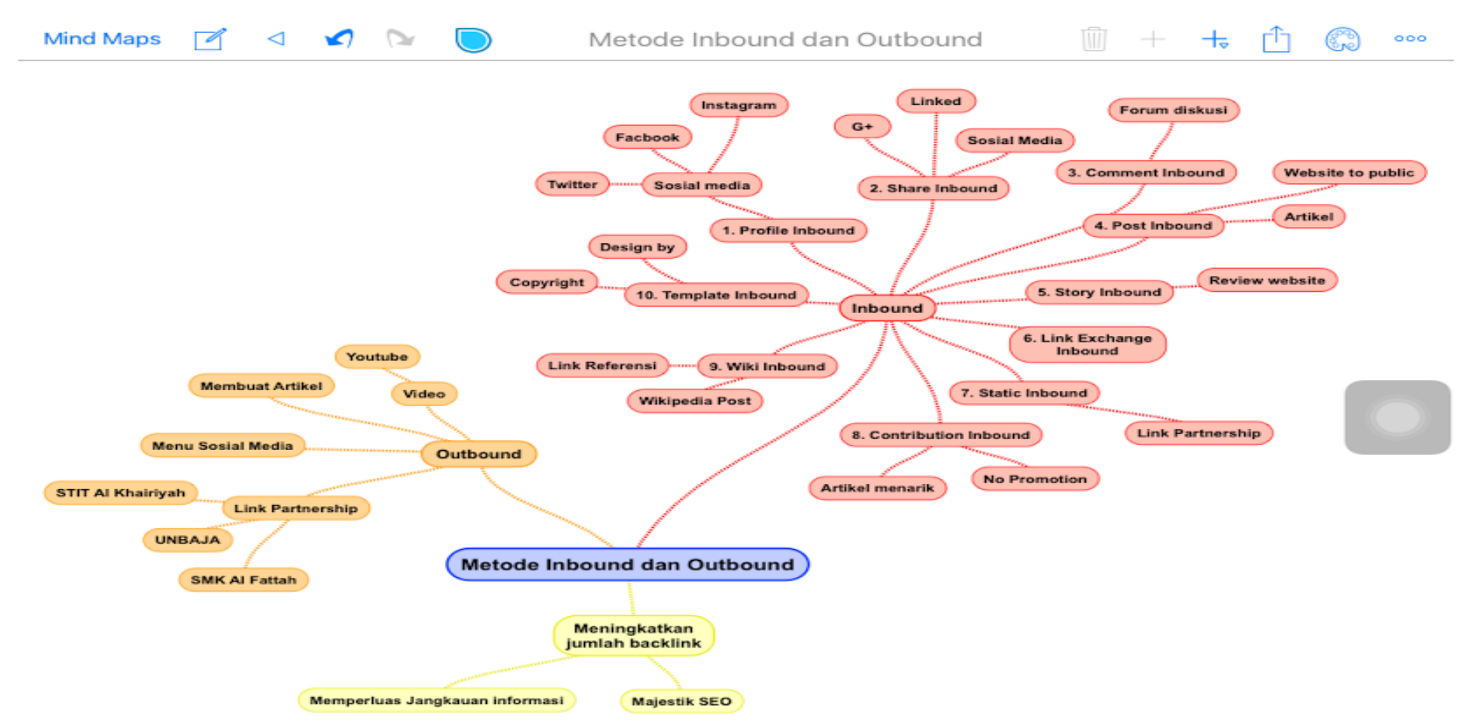

Gambar 3. Mind Mapping perancangan inbound dan outbound

Dilihat dari konsep diatas, pengimplementasiannya terbagi menjadi 3 (tiga) bagian yang terdiri dari inbound, outbound dan bertujuan untuk memperluas jangkauan inforrmasi dan meningkatkan jumlah backlink yang diukur melalui salah satu sistem penghitung backlink yaitu majestic SEO. Dimana pada inbound terdapat 10 level yang sudah dijelaskan sebelumnya serta adanya outbound untuk penempatan link dari luar yang ditampilkan dengan apik pada masingmasing subdomain raharja.ac.id.

Maka dari itu diterapkannya metode inbound dan outbound sebagai jembatan untuk penyebaran link sehingga dapat meningkatkan rank webometrics. Inbound dan Outbound dimana dengan metode ini para webo warriors (Tim sukses webometrics), pada Perguruan Tinggi Raharja dapat melakukan linking dengan lebih mudah dan menyenangkan karena berdasarkan pada 10 level inbound dimana tingkat kesulitan pada ke sepuluh level tersebut dapat menentukan keberhasilan dalam mencapai inbound yang diinginkan, selain itu juga untuk mencapai target yang tepat sasaran. Berikut ini adalah 10 level inbound:

Tabel 3. Level Inbound

\begin{tabular}{|c|c|c|}
\hline No & Level Inbound & Keterangan \\
\hline 1 & Profile Inbound & $\begin{array}{c}\text { Pemanfaatan Profile jejaring sosial seperti facebook, twitter dan instagram dengan } \\
\text { mencantumkan link dari subdomain yang diinginkan }\end{array}$ \\
\hline 2 & Share Inbound & $\begin{array}{l}\text { Sharing informasi baik itu artikel, foto, video ke jejaring sosial. Karena jumlah pemirsa } \\
\text { pada pengguna tersebut bisa menjangkau luas hingga ke seluruh dunia. }\end{array}$ \\
\hline 3 & Comment Inbound & $\begin{array}{c}\text { Banyaknya website yang menyediakan tread sebagai wadah untuk berdiskusi dengan } \\
\text { memberikan kometar, ini menjadi kesempatan untuk menyisipkan link salah satu } \\
\text { subdomain. }\end{array}$ \\
\hline 4 & Post Inbound & $\begin{array}{l}\text { Menulis sebuah artikel ataupun postingan singkat namun padat akan informasi mengenai } \\
\text { salah satu subdomain yang ingin kita ulas lebih di website lain. }\end{array}$ \\
\hline 5 & Story Inbound & $\begin{array}{l}\text { Menceritakan atau menggambarkan bagaimana website yang ingin kita tuju, seperti } \\
\text { review sebuah website. kemudian adanya komunikasi lebih lanjut untuk bisa } \\
\text { menambahkan cerita yang telah dibuat agar dimuat disana. }\end{array}$ \\
\hline 6 & Link Exchange Inbound & $\begin{array}{c}\text { Saling bertukar link (exchange link), Pada level ini bisa memberikan keuntungan satu } \\
\text { sama lain. }\end{array}$ \\
\hline 7 & Static Inbound & website parnership, adanya kerjasama yang di jalin antara kedua situs official site \\
\hline
\end{tabular}




\begin{tabular}{|c|c|c|}
\hline & & dimana masing-masing menampilkan link yang disertai dengan logo partnernya. \\
\hline 8 & Contribution Inbound & $\begin{array}{l}\text { Menjadi kontributor atau menjadi partisipan dalam membuat artikel yang menarik. } \\
\text { Website semacam ini biasanya memiliki auditor, sehingga untur promosi baiknya sedikit } \\
\text { diminimalisir. }\end{array}$ \\
\hline 9 & Wiki Inbound & $\begin{array}{c}\text { Menjadi bagian dari Wikipedia, dapat membuat postingan atau mencantumkan link pada } \\
\text { bagian referensi. }\end{array}$ \\
\hline 10 & Template Inbound & $\begin{array}{c}\text { membuat template untuk konsumsi public. Misalnya membuat sebuah template untuk } \\
\text { blog atau blogspot or wordpress yang selanjutnya menyisipkan link official ke dalam } \\
\text { copyright atau design by. }\end{array}$ \\
\hline
\end{tabular}

Dan untuk outbound, adanya link yang tersebar diseluruh bagian website baik itu artikel, video, bahkan juga link partner yang ditampilkan berupa listing untuk menampilkan link berserta logo partner. Perhitungan visibility didasarkan pada kualitas konten yang di evaluasi berdasarkan kesepakatan umum secara virtual, dihitung dari semua link eksternal web domain.

Pada penjelasan diatas, penulis sudah menjawab apa yang ada dalam permasalahan sebelumnya. Bahwa metode inbound dan outbound telah dapat membangun konsep linking tersebut agar para dosen maupun mahasiswa khususnya tim webo warriors dalam penyebaran linking lebih terarah dan mudah sesuai dengan adanya 10 level inbound dan proses yang mudah dalam penempatan outbund. Selain itu, peningkatan yang ditargetkan berdasarkan indikator inbound webometrics, sebanyak $29 \%$ telah dicapai para webo warriors dari $50 \%$ angka visibility. Hal ini dibuktikan dengan pergeseran diagram sesuai dengan jumlah capaian saat ini hingga bulan Juli mendatang dimana hasil rank webometrics periode ke-2 di tahun 2016 ini akan di publikasikan. Dibawah ini adalah progress status capaian webometrics.

\subsection{Listing Program}

Dalam menghasilkan outbound, dibutuhkan link dari site luar untuk bisa dikemas sedemikian rupa hingga tertata dengan apik pada setiap subdomain dibawah raharja.ac.id. Dan untuk menampilkan sebuah logo yang dapat mengarah langsung ke site lain, maka perlu adanya sebuah listing program yang berguna untuk bisa menjalankan program tersebut. Berikut ini penulis tampilkan listing program yang digunakan untuk menampilkan Partner pada salah satu subdomain yaitu ilp.raharja.ac.id. Dimana pada bagian tersebut terdapat logo yang mengarahke official site dari pihak luar yaitu Universitas Banten Jaya (UNBAJA), dan SMK Al-Fattah pada halaman official site iLearning Plus. Dibawah ini adalah listing program tersebut.

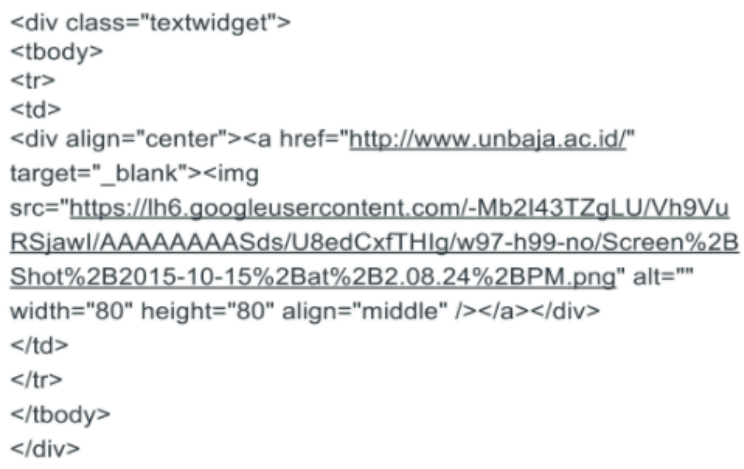

Gambar 4. Listing program untuk menampilkan link dan logo UNBAJA

Dari gambar diatas adalah listing program untuk menampilkan logo Universitas Banten Jaya (UNBAJA) sebagai partner Perguruan Tinggi Raharja, adanya link official site UNBAJA menghasilkan outbound link. 


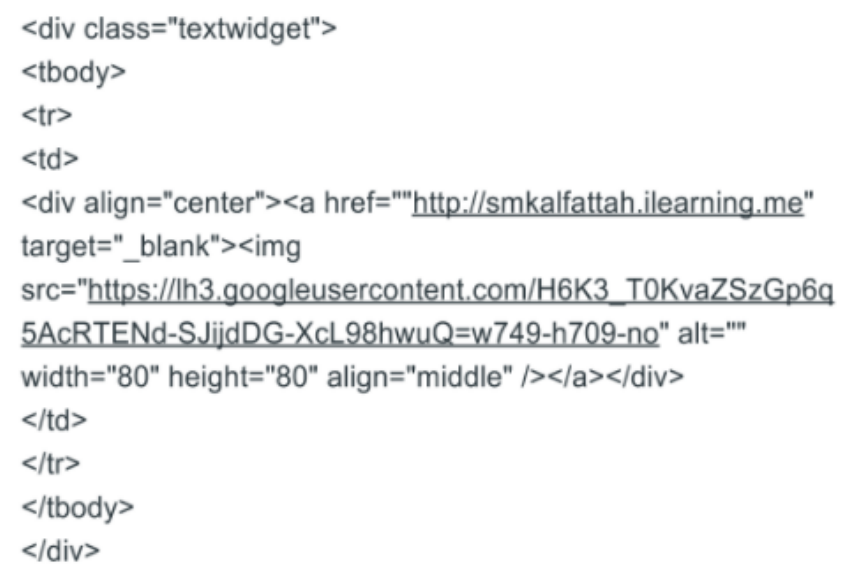

Gambar 5. Listing program untuk menampilkan link dan logo SMK Al-Fattah Berdasarkan gambar diatas adalah listing program untuk menampilkan logo SMK AlFattah sebagai partner Perguruan Tinggi Raharja, adanya link official site SMK Al-Fattah menghasilkan outbound link.

\subsection{Implementasi}

Pada tahap implementasi, pemanfaatan dari banyaknya subdomain yang dimiliki Perguruan Tinggi Raharja adalah peluang besar untuk bisa mencapai peringkat atas pada webometrics, salah satunya dengan memenuhi indikator visibility. Berikut ini adalah tampilan pada halaman awal domain utama raharja.ac.id dan 2 subdomain yaitu_ilp.raharja.ac.id dan $\underline{\text { logistik.raharja }}$

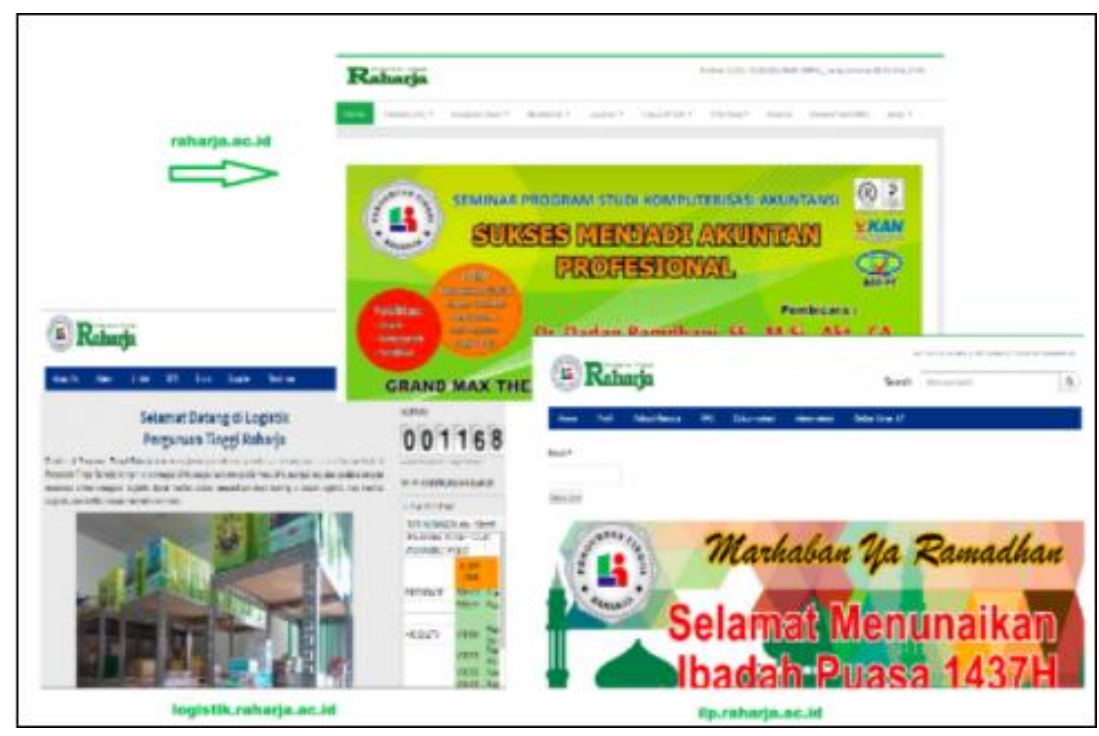

Gambar 6: Tampilan home

Dapat dilihat dari gambar 6 yaitu tampilan home, template yang digunakan pada setiap sub domain sama seperti raharja.ac.id, hal ini untuk keseragaman dan menjadi ciri khas Perguruan Tinggi Raharja.

Penerapan metode inbound dan outbound yang dilakukan berdasarkan 10 level inbound beserta upaya memaksimalkan outbound yang telah tersebar ke banyak website termasuk juga jejaring sosial dan youtube. berikut ini contoh penerapan inbound dan outbound: 


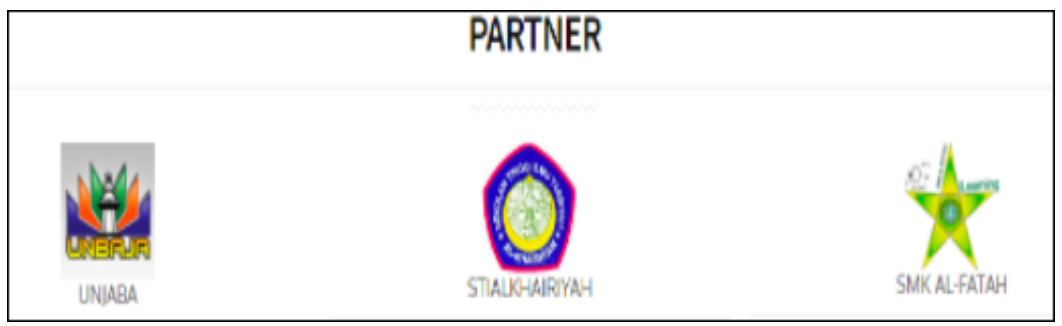

Gambar 7 : Outbound dalam bentuk Partner link

Dilihat dari Gambar diatas bahwa adanya Partner link pada ilp.raharja.ac.id yang menjadi sub domain Perguruan Tinggi Raharja, ini merupakan salah satu cara untuk meningkatkan jumlah linking.

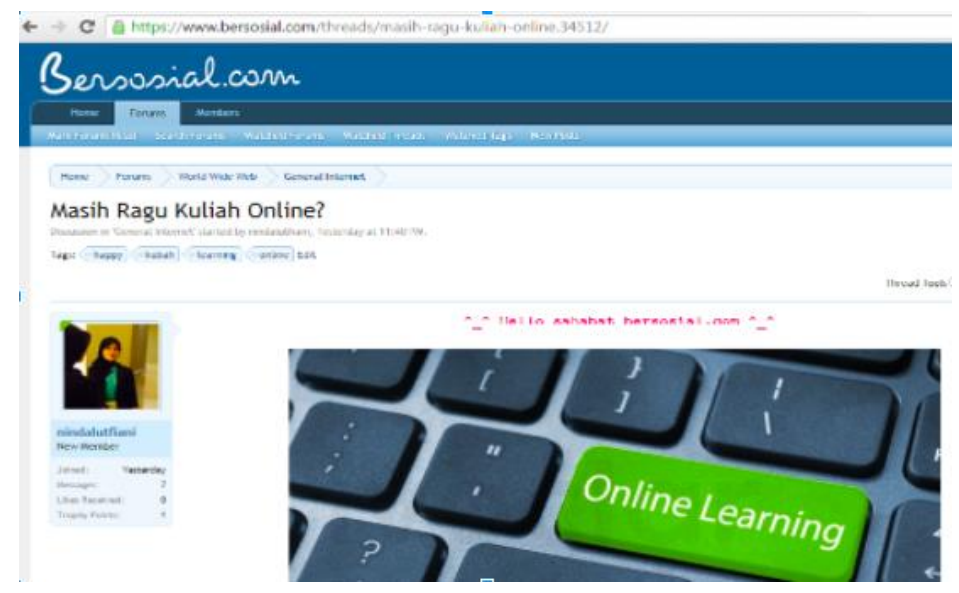

Gambar 8: Inbound link

Pada gambar diatas adalah adalah proses penyebaran inbound link pada subdomain ilp.raharja.ac.id menggunakan level 4 yaitu post inbound. Membuat postingan pada site lain dengan menyisipkan link ilp.raharja.ac.id.

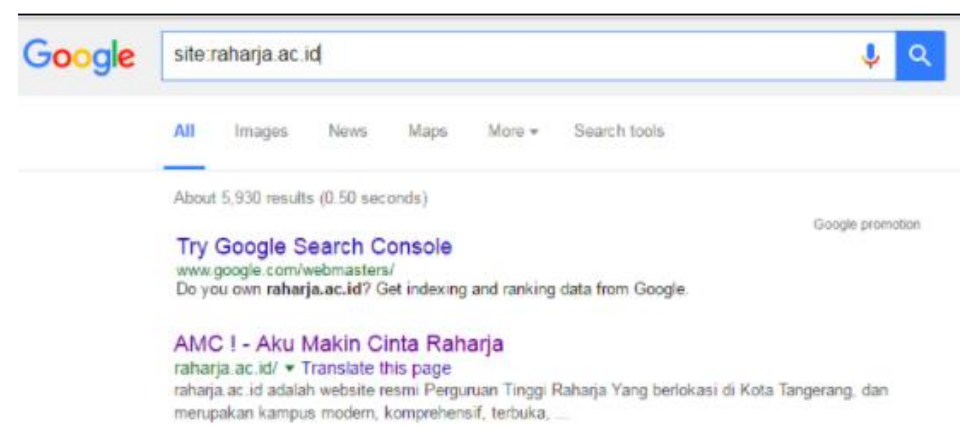

Gambar 9: Hasil pencarian pada Google sebanyak 5.930

Setelah melakukan penyebaran link, hasil pencarian pada mesin pencari juga terus diamati. Seperti yang tergambar di atas bahwa hasil pencarian pada Google mnunjukkan angka hingga 5.930 dari jumlah sebelumnya sebanyak 4630 hasil pencarian .

Data dikumpulkan melalui metode observasi, pada tahap ini dilakukan dengan mengamati perilaku mesin pencari dalam melihat jumlah backlink dari pihak ketiga melalui hasil pencarian dengan mamasukkan keyword site:raharja.ac.id, pencapaian anchor melalui perhitungan grafik anchor text melalui majestic.com dan hasil perhitungan backlink pada semrush.com, sebagai berikut. 


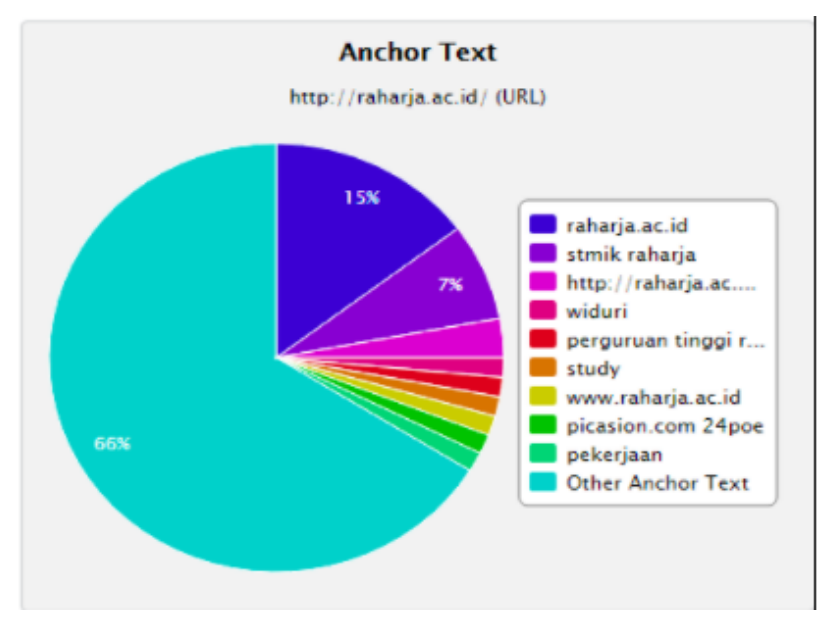

Gambar 10: Grafik Anchor Text pada majestic.com

Dari langkah-langkah strategi yang dilakukan, situs MajesticSEO menghitung jumlah reference domains dari situs educational (berakhiran .edu atau ac.id). Jumlah peningkatan pada link raharja.ac.id mendapatkn hasil sejumlah $15 \%$ peringkat URL.

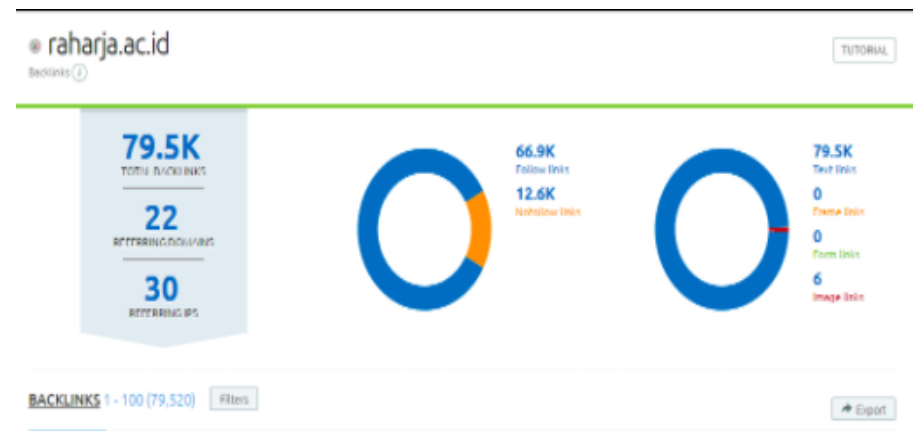

Gambar 11: hasil perhitungan backlink semrush.com

Seperti pemeringkatan URL, semrush menunjukkan jumlah dan kualitas dari backlink. Hasil dari implementasi mulai dari proses inbound dan outbound link, analisa melalui Majestic dan semrush yang dijalankan selama bulan April sampai dengan Juli 2016, telah membuahkan hasil dengan meningkatnya peringkat Perguruan Tinggi Raharja pada pemeringkatan Webometrics edisi Juli 2016.

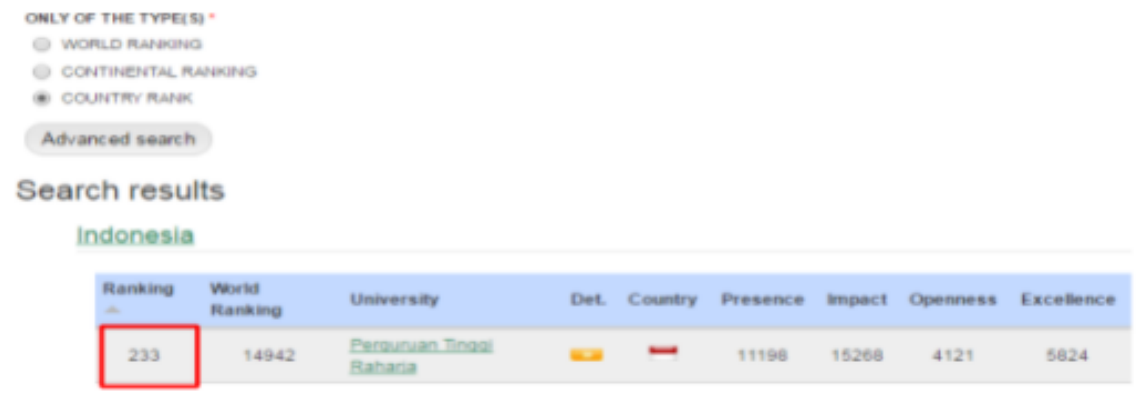

Gambar12: Peringkat Webometrics Edisi Juli 2016

Berdasarkan gambar diatas dapat dilihat bahwa jumlah ranking pada edisi bulan Juli 2016 ini menjadi 233 dari capaian sebelumnya 303. Selain itu jumlah impact/visibility yang juga menjadi fokus bahasan naik hingga 15.268 dari jumlah capaian sebelumnya yaitu 19.730 
impact. hal ini menandakan capaian yang didapat dari strategi inbound dan outbound yang diterapkan dapat berhasil secara signifikan.

\section{KESIMPULAN}

Berdasarkan penelitian diatas dapat disimpulkan bahwa metode inbound dan outbound dapat meningkatkan jumlah backlink secara efisien. Disamping itu, penerapan metode ini dinilai menarik karena sangat mudah diterapkan yang didukung dengan adanya 10 level inbound dan proses dalam menanamkan link outbound yang sangat mudah dilakukan dengan membuat artikel, membuat link partner, membuat video dan lain sebagainya. Pencapaian webometrics setelah melalui proses implementasi ibound dan outbound link dengan memaksimalkan indikator visibility telah berhasil meningkatkan peringkat Perguruan Tinggi Raharja dari sebelumnya 303 menjadi 233. Menjadi bagian dari webometrics penting adanya untuk melihat seberapa jauh kualitas dari website dan kekayaan digital yang dimiliki oleh Perguruan Tinggi Raharja. Penerapan inbound dan outbound sebagai salah satu bagian dari indikator visibility terbukti dapat meningkatkan rank dengan selisih sebanyak 70 tingkat.

\section{SARAN}

Adapun saran untuk penelitian selanjutnya agar lebih mengembangkan metode inbound dan outbound link dengan memperluas penyebaran link baik itu pada domain utama ataupun setiap subdomain ke berbagai situs yang ada di internet. Konsistensi untuk terus meningkatkan jumlah linking, akan mendukung mwningkatnya indikator visibility dalam pemeringkatan webometrics.

\section{UCAPAN TERIMA KASIH}

Penulis mengucapkan terima kasih kepada STMIK Raharja yang telah memberi dukungan finansial terhadap penelitian ini.

\section{DAFTAR PUSTAKA}

[1] Wahyuningrum, Tenia. (2015). Strategi Peningkatan Visibility Dalam Rangka Peningkatan Ranking Webometrics. Seminar Nasional Teknologi Informasi dan Komunikasi (SENTIKA), 151-156. Diambil dari https://fti.uajy.ac.id/sentika/publikasi/makalah/2015/19.pdf

[2] Adedapo, A. (2015). Webometrics Rangkings As Informer Of Public On University Education: Some Implication For Nigeria's Economic Growth. European Journal Of Educational Studies, 7(1). Diambil dari http://anadolu.dergipark.gov.tr/ejes

[3] Jeyashree, S., \& Ravichandran, R. (2013). Perspectives of Webometric Tools for Web Impact Assessment Studies: A Review. International Journal of Library Science, 2(2), 43-48. Tersedia di http://article.sapub.org/10.5923.j.library.20130202.03.html

[4] Osunade, O., \& Ogundele, C. O. (2012). Valuation of the university of Ibadan website using webometric ranking parametars. Transnational Journal of Science and Technology, 2(3), 66-78. Tersedia di http://www.tjournal.org/tjst_april_2012/c5.pdf

[5] Vaughan, L., \& Yang, R. (2013). Web traffic and organization performance measures: Relationships and data sources examined. Journal of informetrics, 7(3), 699-711. Tersedia di http://www.sciencedirect.com/science/article/pii/S1751157713000412 